Journal of Social Sciences 7 (1): 13-23, 2011

ISSN 1549-3652

(C) 2010 Science Publications

\title{
Higher Education for Sustainable Development: Students' Perspectives on an Innovative Approach to Educational Change
}

\author{
Matthias Barth and Jana-M. Timm \\ Institute for Environmental and Sustainability Communication, \\ Leuphana University of Lüneburg, Scharnhorststraße 1, 21335 Lüneburg, Germany
}

\begin{abstract}
Problem statement: With Higher Education for Sustainable Development (HESD) being an innovative approach to educational change, its principal objective is students' development of transformation competencies. However, HESD evaluations hardly consider students' perspectives. This study presents a study that examined undergraduate students' view on the HESD approach at the Leuphana University of Lüneburg (Germany) and aims at shedding light on their acceptance and perceptions of such an HESD learning setting. Approach: For this purpose, two corresponding surveys were carried out that analyzed the impact of such a curriculum design on undergraduate students of the 2nd and 4th semester. Results: A high rate of $75.4 \%$ of the undergraduate students indicated their commitment towards the Leuphana University study model. Simultaneously they showed a sophisticated understanding of the concept of sustainability and agreed with the values associated. Comparing the results of three different student groups with variation in the degree of sustainability related studies, a group of students studying sustainability in their minor as a second subject beside disciplinary oriented studies showed a significant higher acceptance rate than their study peers. Conclusion: These results suggest that the Leuphana University holistic HESD education approach may not only be attractive to inherently sustainability affiliated prospective students but particularly also to open, tolerant and cosmopolitan young people that are interested to attend interdisciplinary sustainability studies besides their major study subject. Thus, the learner-centered approach is connected to students' lifeworld experience, which provides an opportunity to also attract those students that might be less familiar with the sustainability concept.
\end{abstract}

Key words: Sustainability education, Higher Education for Sustainable Development (HESD), curriculum change, student survey, Education for Sustainable Development (ESD)

\section{INTRODUCTION}

The future oriented concept of sustainable development, by now firmly established in international political discourse, clearly poses a challenge that asks for a societal reorientation on different levels. The integrative examination of the exploitation of natural resources on the one hand and both environmentally friendly and socially just economic development on the other hand mark a focal point of that discourse, together with questions of inter- and intra-generational justice in a globalized world.

Universities in their roles of researching and teaching institutions as well as regionally rooted employer and consumer are playing a crucial role in the context of sustainable development, since they (1) educate societies' future decision makers providing them with key competencies to contribute to a (more) sustainable future and also (2) generate, transfer and communicate new knowledge reflecting on and simultaneously innovating, society (Cortese, 2003; Gough and Scott, 2007; Fien, 2002; Moore, 2005). Orr (1994) illustrates the important role university graduates perform in society by arguing that society's current social and ecological development trends are "not the work of ignorant people. It is, rather, largely the result of work by people with BAs, BSs, LLBs, MBAs and PhDs". However, the implementation of an overall concept of sustainable development brings with it new challenges for higher education: "Without new approaches in teaching, the new academia is not imaginable. Well-trodden paths and approaches need to be checked and abandoned, in case of doubt” (Gruppe 2004).

Higher education for sustainable development: Against the background of globalization and increasing complexity, Higher Education for Sustainable

Corresponding Author: Matthias Barth, Institute for Environmental and Sustainability Communication, Leuphana University of Lüneburg, Scharnhorststraße 1, 21335 Lüneburg, Germany 
Development (HESD) aims at the individuals' competencies not only to collect and generate knowledge but also to reflect on the complexity and interrelations of behavior as well as decision-making in a future-oriented and global perspective (Adomssent and Michelsen, 2006; Barth and Godemann, 2006). Taking this into account, Education for Sustainable Development (ESD) is "not just another issue to be added to an overcrowded curriculum, but a gateway to a different view of curriculum, of pedagogy, of organizational change, of policy and particularly of ethos" (Sterling, 2004). Implementing HESD thus means re-adjusting academic teaching and offering new learning settings.

The aim of such a re-adjustment of existing curricula is to design learning settings that ask for ethically reflected decision-making, bridges disciplinary knowledge and interdisciplinary, problemoriented approaches and allows for the integration of different types of knowledge for solutions of practical relevance.

For such a re-design, at least four learning goals need to be considered:

\section{Learning goals:}

Inter-and transdisciplinary problem-solving: Sustainability-related problems will not be solved by taking into account only one discipline by itself. There is a need to link knowledge of structures and interrelations with ethical orientations and anticipatory thinking. Thus what is needed in higher education is interdisciplinary settings that integrate stakeholders and work close to a specific real-life context.

Dealing with complexity: Higher education has to familiarize students with the changeability of complex systems so that they understand better society and its development against the background of an increasingly complex and interrelated world.

Self-directed, collaborative learning: ESD is an open process of negotiation that calls for reflexive group discussions. Furthermore, to support the development of competencies, self-directed learning processes will be required.

Competence development: In today's society individuals have to handle complex situations and to consider different consequences while at the same time being able to decide and act reflexively. HESD therefore needs to support the development of relevant competencies by combining meaningful interdisciplinary topics with innovative learning settings.

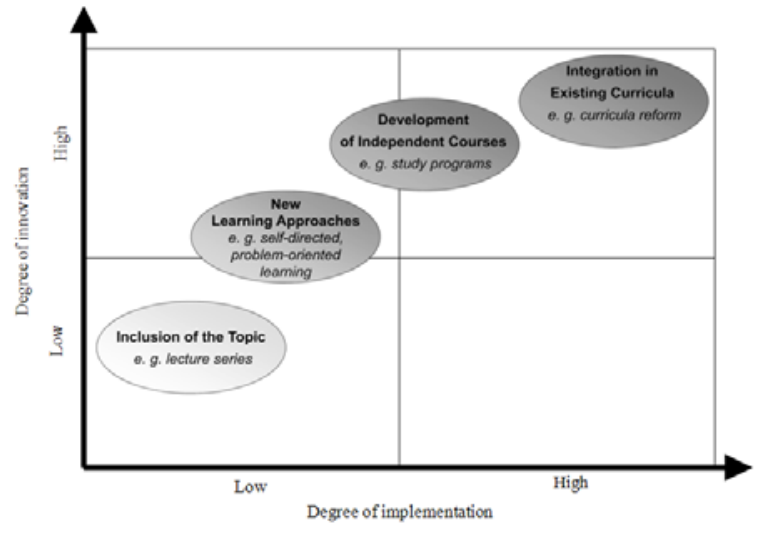

Fig. 1: Steps of integration of sustainable development in higher education

Integrating sustainable development into the curriculum: The implementation of ESD in higher education is the subject of numerous case studies that analyze different approaches of integration (Blewitt and Cullingford, 2004; Corcoran and Wals, 2004; Leal, 2000). Considering both the degree of innovation and the degree of implementation, at least four different types of implementation may be distinguished. These approaches, as illustrated in Fig. 1, are partly based on one another and describe steps of a pathway towards a deep-rooted implementation. However, this does not mean that all the different steps have to be taken.

The first and most simple form of integration consists of an inclusion of sustainability-related topics in conventional learning settings like a lecture series. Such an approach offers the opportunity to introduce new topics and in particular enables different disciplines to contribute. A closer integration of sustainable development in higher education also needs new learning approaches like self-directed and problem-oriented learning that supports competence development. Taking into account the insight that knowledge cannot simply be transferred but must be both individually generated in specific situations and based on previous experiences, conditions for selfdirected knowledge-generation must be provided.

While these two approaches allow for new topics as well as new methods, an even closer implementation needs the development of independent courses, such as specific study programs. These include approaches like project-oriented studies as well as interdisciplinary programs that are open to innovative didactical approaches as well as topics that cannot be covered by a single discipline.

The most far-reaching approach with the highest degree of implementation comes with an integration of 
the topic in the general curriculum of the university. Thus, the aim may be a general orientation on the overall concept of sustainable development as a guiding principle of higher education.

By now, the general idea of HESD and its importance has been widely accepted and enjoys political support. As a result, a wide variety of implementation strategies, a number of different initiatives and pilot projects have been initiated all over the world within the last decade considering sustainable development as an important issue of higher education. In terms of integration into the curricula, sustainability has been primarily adopted in the form of new study programs and specific courses that have sustainable development as their focus topic. Still, only a few higher education institutions have dared to tackle the challenge of reorienting a university's entire educational concept (Sterling, 2004).

Many university efforts in HESD from all over the world are presented in the form of case studies in books and scholarly journals. Also, environmental education and environmental research journals, such as the Journal for Environmental Education Research, the Journal for Environmental Education and the Journal of Cleaner Production have published case study articles on HESD. All these publications portray or review different university experiences. From the available literature, the present authors were able to identify seven types of case studies, which portray:

- Universities' sustainability performances and ecological footprints, mostly using predetermined sets of sustainability indicators;

- Universities' approaches to integrating sustainability into their curricula, either in a holistic approach for the whole university or for specific programs, such as engineering courses;

- Universities' approaches to integrating sustainability into on-campus practices;

- experiences of on-campus university or student initiatives;

- Universities' approaches to integrating sustainability into on-campus practices;

- experiences of on-campus university or student initiatives;

- University experiences in the constitution of Regional Centers of Expertise (RCE);

- One-time surveys about students' environmental or sustainability literacy;

- Pre-and post-surveys of students' environmental or sustainability literacy, mainly to measure the impact of a single program, course or field trip on students' sustainability literacy
The last two types of case studies identified refer to case studies about students; however, those are usually very specific surveys focusing on specific study subjects, such as pedagogy or engineering. Hence, the conducted literature review correspond with other scholars' publications on HESD implementation: Thus far, research and case studies in HESD have been focusing on organizational change aspects within the implementation processes, the role of staff and teachers and their acceptance of HESD as well as the potential of innovation for higher education (Brand and Karvonen, 2006; Fien, 2002; Corcoran et al., 2004; Wright, 2006; 2007). It is only gradually that the theoretically grounded description, explanation and improvement of the learning process are coming into the focus of HESD, with an emphasis on descriptive approaches but a general lack of theory development (Barnett, 2004; Seybold and Rieß, 2006; Tilbury, 2004). Consequently, a considerable body of criticism centers on the limited possibilities of generalizing the more or less descriptive findings and verifying findings from the outside (Corcoran et al., 2004; Fien, 2002).

Recent work on HESD has been taking up those challenges and is developing a theoretical grounded concept for the integration of sustainable development in higher education (Scott and Gough, 2003; Tilbury, 2004) or is working on meta-studies that review existing empirical findings (La Harpe and Thomas, 2009; Gough and Scott, 2007; Thomas, 2004). The main focus here is on organizational aspects, in work that recognizes sociological organizational theory as well as teacher-oriented research. However, what is rarely considered is student oriented aspects of perception and acceptance as well as the impact on learning processes and their learning outcome. This article, therefore, presents a case study of students' perspectives on the educational concept of HESD, revealing the students' acceptance of its implementation process and indeed HESD itself at the Leuphana University of Lüneburg (Leuphana).

The case of Luneburg: implementation of HESD: In recent years, the Leuphana has carried out the necessary restructuring of the existing higher education curriculum within the framework of the so-called Bologna process as an opportunity to fundamentally change its courses of study (see Heinze/Knill 2008 for more information about the Bologna-process). Within this process, the consideration of sustainable development as a guiding principle played a crucial role, consistently continuing the development of the University towards a 'sustainable university', whose development may be described according to its 
organizational change, the formation of a research cluster 'Sustainable Development' and the change in the university's curriculum (Adomssent and Beringer 2008 for more information on milestones like the project 'Agenda 21 and the University of Lüneburg (1999-2001), the research and development project 'Sustainable University-Sustainable Development in the context of university remits' (2004-2007) and the inauguration of the UNESCO-Chair Higher Education for Sustainable Development). Thus, sustainability has been integrated in higher education in a development following the four steps: from the introduction of an interdisciplinary lecture series to the development of new forms of teaching and learning to a full integration into the university's curriculum. This article focuses on the last stage and analyses the Bachelor study courses of Leuphana College.

Leuphana bachelor: The reorientation of university curricula under the framework of the Bologna Process was used to implement previous experiences in HESD.

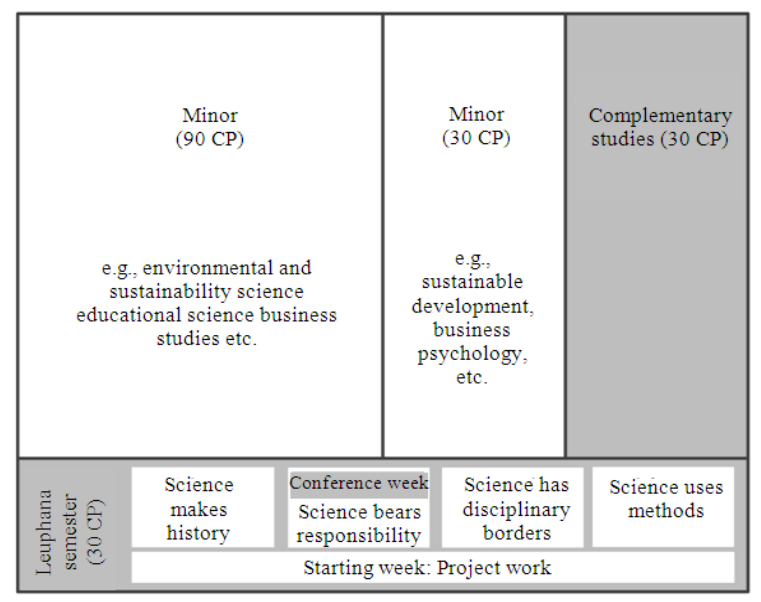

Fig. 2: Leuphana study model including the Leuphana Semester

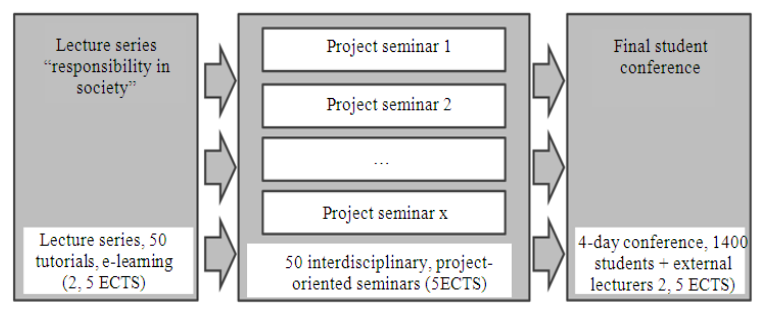

Fig. 3: Structure of the module 'Science bears Responsibility'
Since the winter semester of 2007/08, all Bachelor programs have followed a single study model, which consists of a Major, a Minor, complementary studies and the Leuphana Semester as the first study semester (Fig. 2). Thus, the Leuphana Bachelor is characterized by a compulsory module on sustainability for all students in the first semester and, on top of that, offers different options to deal with sustainability in optional courses: either as a Major in 'environmental and sustainability science' (90 ECTS) or as a Minor in 'sustainable development' (30 ECTS).

Leuphana Semester: All 1,400 first semester students start their studies with the 'Leuphana Semester', a general studies module and experience interdisciplinary studies, which begin with a week of project work that is followed by four modules (Fig. 2). Besides an introduction to the discipline of the students' major subject, the modules deal with aspects of history and philosophy, with questions of social responsibility and deliver a first insight into scientific methods. The Leuphana Semester ends with a four-day conference on sustainability, where all interdisciplinary student groups present their project work.

Module 'science bears responsibility': One third of the first semester is completely devoted to the topic of sustainability. Students of all subjects work under the overall theme of 'Science bears Responsibility' on the question how the concept of sustainable development may be used as a normative framework for responsible action. The goal is to promote the personal development of the students as well as to enable them to cope with complex situations and to make meaningful decisions.

Within the module, students have the opportunity to carry out an in-depth examination of a comprehensive topic, regardless of their disciplinary orientation. The module is structured in three parts according to the principles of knowledge generation and presentation (Fig. 3): First, a series of lectures with parallel tutorials and an e-learning module introduce the overall topic of sustainable development (workload: 75h). The concept of sustainable development is established as a normative framework for dealing with different aspects of responsibility in the society.

In a second step of knowledge generation, students' responsibility for their own learning process is supported by offering specific project work to examine different aspects of sustainability. Thus, the general topic is broken down into about 50 different project 
seminars with a broad variety of focal points (workload: 150 h). Finally, the module finishes with a 4 day conference, organized by the students themselves with different presentation forms and invited experts, which integrates the different approaches into an overall picture. About 250 different projects are presented and the broad variety of presentation forms visualizes the creative potential of students (workload: $75 \mathrm{~h}$ ).

\section{MATERIALS AND METHODS}

Aim of the study: Even with students' competence development as a core objective of HESD, students' perception and view on ESD is rarely taken in consideration. The present study aims at bridging that gap by examining the students' view on Leuphana's HESD implementation process as well as their acceptance and perceptions in such an HESD learning setting. For this purpose, two surveys were carried out that analyzed the impact of such a curriculum design on students. More specifically, the following two main research questions were addressed:

- How is a curriculum change towards sustainability perceived and acknowledged by the students?

- What knowledge, values and beliefs do different students have with different foci on sustainability in their studies?

Empirical design of the study: Given these research questions, two complementary surveys were conducted. The first was made at the end of the winter semester 2008/09 as part of the modules evaluation with a response rate of $93.3 \%$ of all students. In it, students were asked for their acceptance and perception of the different learning settings. Table 1 shows the different study courses (major) within the bachelor program.

At the beginning of the summer semester 2009, a second study was conducted. The aim was to survey the first (2007/08) and the second (2008/09) cohorts that had experienced the new university curriculum. It considered three different target groups: (1) students studying sustainability-affiliated studies in their major (SD Major), (2) students studying sustainabilityaffiliated studies in their minor (SD Minor) and (3) students studying sustainability neither in their major nor in their minor (SD Non). While time and resources allowed a complete survey for the first and second groups, a sample survey only was done for the third and much larger group of students.
Table 1:Study Courses on offer and respective student numbers in summer semester 2009

\begin{tabular}{lc}
\hline Study Courses & N (sec. sem) \\
\hline Culture science & 201.000 \\
Business studies & 247.000 \\
Business informatics & 39.000 \\
Engineering & 101.000 \\
Social pedagogy & 56.000 \\
Environmental science & 79.000 \\
Economics & 31.000 \\
Business psychology & 99.000 \\
Business law & 81.000 \\
Teacher education & 270.000 \\
Total & 1.204 \\
\hline
\end{tabular}

Table 2: Empirical design of both studies: an overview

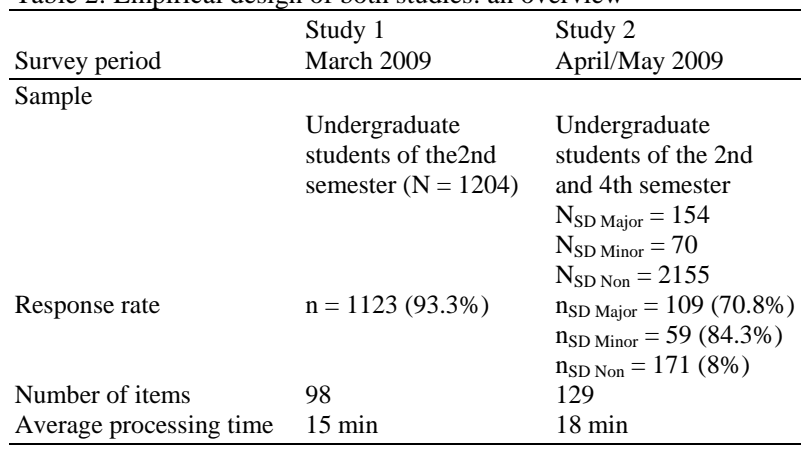

That second study complemented the findings of the first study and gave a deeper insight into interrelations of chosen study courses and sustainability-related knowledge, values and beliefs of students. Table 2 gives an overview of the implementation of the surveys showing some background data.

\section{RESULTS}

Acceptance and perception of the Leuphana study approach: Students' perception and acceptance of the Leuphana study model is reflected in the level of their support of it and the positive assessment results reflected in their decision to study at Leuphana. Respondents reported with $75.4 \%$ that they like the study model. Similarly, $79.5 \%$ of the students "feel like made a good choice by choosing the particular university for their studies".

To find out about significant differences in the perception and acceptance of the study model by the three student groups (SD Major, SD Minor and SD Non), each of the three groups was tested against the other using the two-way Mann-Witney test. Results showed that SD Minor students liked the new study approach significantly more than their SD Non peers (p $=$ 0.039). Likewise, $\mathrm{SD}$ Minor students were 
significantly surer that they had made the right choice by selecting Leuphana for their studies than SD Major students $(p=0.002)$, the difference to SD Non students showed to be even highly significant $(p=0.001)$.

Feedback on students' acceptance of the module on sustainable development was collected in two ways: First, both the entire module and the different forms of learning were evaluated by the students using school grades from 1 (best) to 6 . Second, the acceptance of the didactical key elements underlying the module was rated on a four-point Likert-Scale.

The overall feedback on the module is positive: the entire module was rated with a mean value of $2.2(2=$ "good") while the different forms of learning had a score from 1.9-2.7. Table 3 shows the respective mean values and standard deviations. Throughout, feedback was best for small-scale learning settings like tutorials and seminars, which are more interactive than largescale lectures and individual e-learning. Mean values differed slightly with students who had the course as a major, from 1.8 (major environmental science) to 2.7 (major business informatics), reflecting the majors' affinity to the overall topic of sustainability.

The didactical key elements of (1) interdisciplinarity, (2) problem-orientation and (3) selfdirected learning were given a predominantly positive assessment. While $74.8 \%$ of the students agree/strongly agree that they can benefit from the interdisciplinary learning opportunities, $68.3 \%$ do so for problemoriented and still $65.3 \%$ for self-directed learning.

Considering students' major study course, significant differences were found between four groups of students. While the cluster of environmental science, culture science and business psychology was highly positive on all three topics, a second cluster of students studying economics, business studies, business law and business informatics gave ratings nearly as high to problem-orientation, but significantly lower to interdisciplinary and self-directed learning. In contrast, a cluster of students from social pedagogy and teaching assigned high ratings to interdisciplinary but significantly lower ones to both problem orientation and self-directed learning. The lowest scores were given by a cluster of engineering student.

Sustainability literacy: Students' sustainability-related knowledge was gathered in two ways. On the one hand, students were asked for their understanding of the meaning of the term 'sustainability' and on the other they were asked to rate the most important issues in the discussion about sustainable development in our society. In both cases, a maximum check number of four answers out of a variety of alternative answers had been given. As before, the three different student groups were analyzed. The two-way Mann-Witney significance test was used to find out differences in their knowledge about and attitude towards sustainability.

Students understanding of 'sustainability': The results showed that students put a general emphasis on environmental or ecological aspects, with this focus being followed by the social and generational justice dimension in their understanding of the term 'sustainability'. However, looking into students' major studies, significant differences between the three groups could be found, especially in their understanding of the term with regard to the role of economic growth and societal participation in decision processes. While SD Non students assigned highly significantly greater importance to economic growth $(\mathrm{p}=0.001)$, the emphasis they put on societal participation was significantly less $(p=0.000)$ than their SD Major peers. At the same time, SD Minor students attached a significantly higher importance to the socialgenerational perspective of sustainability than their SD Non peers. Although it was found that the three groups exhibited distinctive tendencies in their understanding of the sustainability concept, this finding indicates no structural but rather gradual differences between the three students groups (Table 4).

Most important sustainability issues: In terms of students' sustainability literacy and their attitude towards sustainability issues in politics and the economy, a cluster analysis for dichotomous variables was conducted using the WINMIRA (2001) software. By using the first item ('qualitative instead of quantitative consumption') as the central differentiator, the analysis revealed structural differences that divide the student sample into two groups. The first group is characterized by a high affinity towards technology and economic efficiency and a high association of a sustainable future with the state's and industry's responsibility. The second group is rather oriented towards different ways of consumption and the individual's responsibility for a more sustainable future (Fig. 4).

Table 3: Acceptance of different module parts: means and standard deviations $(n=1123)$

\begin{tabular}{ll}
\hline Form of learning & Mean (SD) \\
\hline Lectures & $2.7(1.45)$ \\
Tutorials & $1.9(0.86)$ \\
E-learning & $2.3(1.36)$ \\
Seminars & $2.1(0.96)$ \\
Entire module & $2.2(1.05)$ \\
\hline
\end{tabular}

Rating in school grades from 1 (best) to 6 


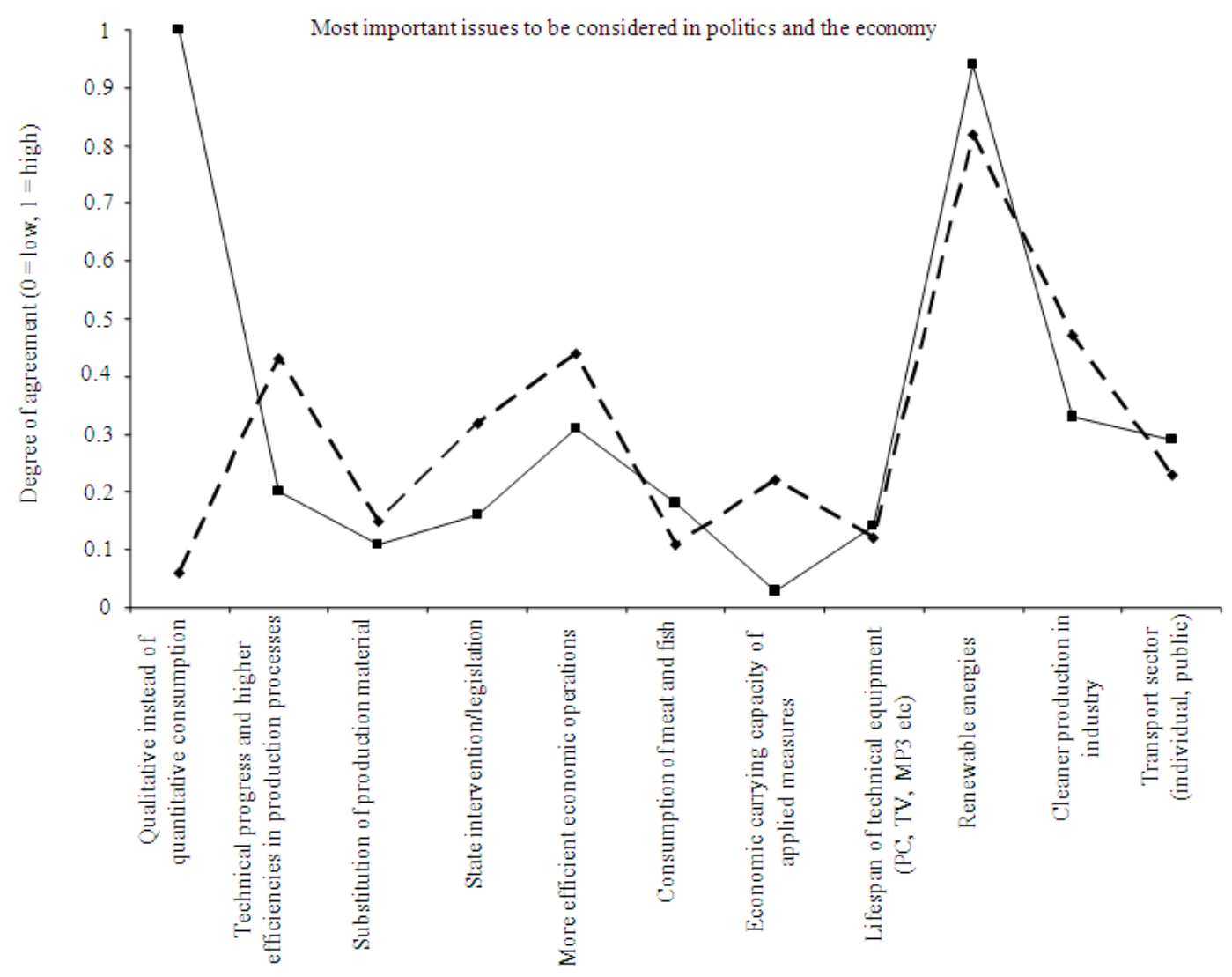

Fig. 4: Structural differences in two group analysis

Table 4: Students understanding of the term sustainability*

\begin{tabular}{|c|c|c|c|c|c|c|}
\hline \multirow[b]{2}{*}{ Characteristics } & \multicolumn{6}{|c|}{ Student group (Ranking, \% within student group) } \\
\hline & SD Non & (\%) & SD Minor & (\%) & SD Major & (\%) \\
\hline Inter- and intergenerational equal opportunities & 3 & 62.10 & 2 & 77.60 & 3 & 64.20 \\
\hline Competiveness of companies in market & 9 & 7.70 & 9 & 6.90 & 9 & 5.50 \\
\hline $\begin{array}{l}\text { Social equal opportunities for people in developing, transition } \\
\text { and developed countries }\end{array}$ & 4 & 47.30 & 4 & 58.60 & 4 & 54.10 \\
\hline Saving of the local, regional and global ecologic systems & 1 & 74.60 & 1 & 81.00 & 1 & 86.20 \\
\hline $\begin{array}{l}\text { Economy functions that allow a lasting and sustainable basis } \\
\text { for acquiring prosperity }\end{array}$ & 6 & 30.20 & 6 & 22.40 & 6 & 26.60 \\
\hline Not using more resources than can grow again in the same time & 2 & 72.20 & 3 & 69.00 & 2 & 70.60 \\
\hline Saving of different cultures in the world & 5 & 30.80 & 5 & 32.80 & 7 & 23.90 \\
\hline $\begin{array}{l}\text { Global economic growth that allows high quality of life for as } \\
\text { many people as possible }\end{array}$ & 7 & 16.00 & 8 & 12.10 & 8 & 2.80 \\
\hline Participation of all societal members in decision processes of society & 8 & 13.60 & 7 & 19.00 & 5 & 31.20 \\
\hline
\end{tabular}

Given that the answers checked by SD Major and SD Minor students turned out to be rather similar (with only one significant difference in checking frequency for the answer 'consumption of meat and fish'), the results of those two student groups were combined. The goal was to enable a comparison of only two students groups (instead of three): (a) students studying sustainability either as their major or minor and (b) students who do not study sustainability at all (Fig. 5). This grouping allowed the preparation of a diagram that can be compared with the diagram resulting from the previous analysis for structural differences.

Comparing the lines of the two diagrams, similarities in shape can easily be spotted. Both graphs 
also exhibit a similarly clear difference between the two student groups in the belief in economic efficiency for a more sustainable future. Moreover, there is an evident tendency of Major/Minor SD students to associate a sustainable future with individual responsibility, as did the second group in the first analysis. However, the two diagrams show a difference in 'state interventions' and 'industry’s cleaner production responsibility'. Yet, results suggest that there is a structural difference between, (1) students studying sustainability in their major or minor and (2) those that have chosen different major and minor courses. While the latter assign high importance to economic operations and efficiencies, the former group puts higher emphasis on individual responsibility in consumption patterns.

Relevance of sustainability in private life and professional career: $28.5 \%$ of the students indicated that sustainability had already been playing a 'strong' or 'very strong' role in their professional goals before they started studying and $35.7 \%$ said so for their private life. This finding is in line with the previous knowledge students have about sustainability. $22.4 \%$ of the SD Non, $49.2 \%$ of the SD Minor and $47.3 \%$ of the SD Major students had encountered sustainability before they started studying, adding up to a total of $35.1 \%$ of all students, with highly significant differences when SD Non are compared with the two other groups $(\mathrm{p}=$ 0.001 and 0.000 ).

The knowledge about sustainability students have acquired throughout their studies was seen as useful for their professional future by $75.4 \%$ of the Bachelor students surveyed.

Breaking down these results into the three student groups, they show highly significant differences. First, a stair-like increase from SD Non students to SD Major students can be observed. While the latter showed the strongest consideration of sustainability in their professional goals before study start, the former gave it the fewest thought for their career.

As for the other two aspects, SD Major and SD Minor students showed similar high results compared with the non-sustainability student group.

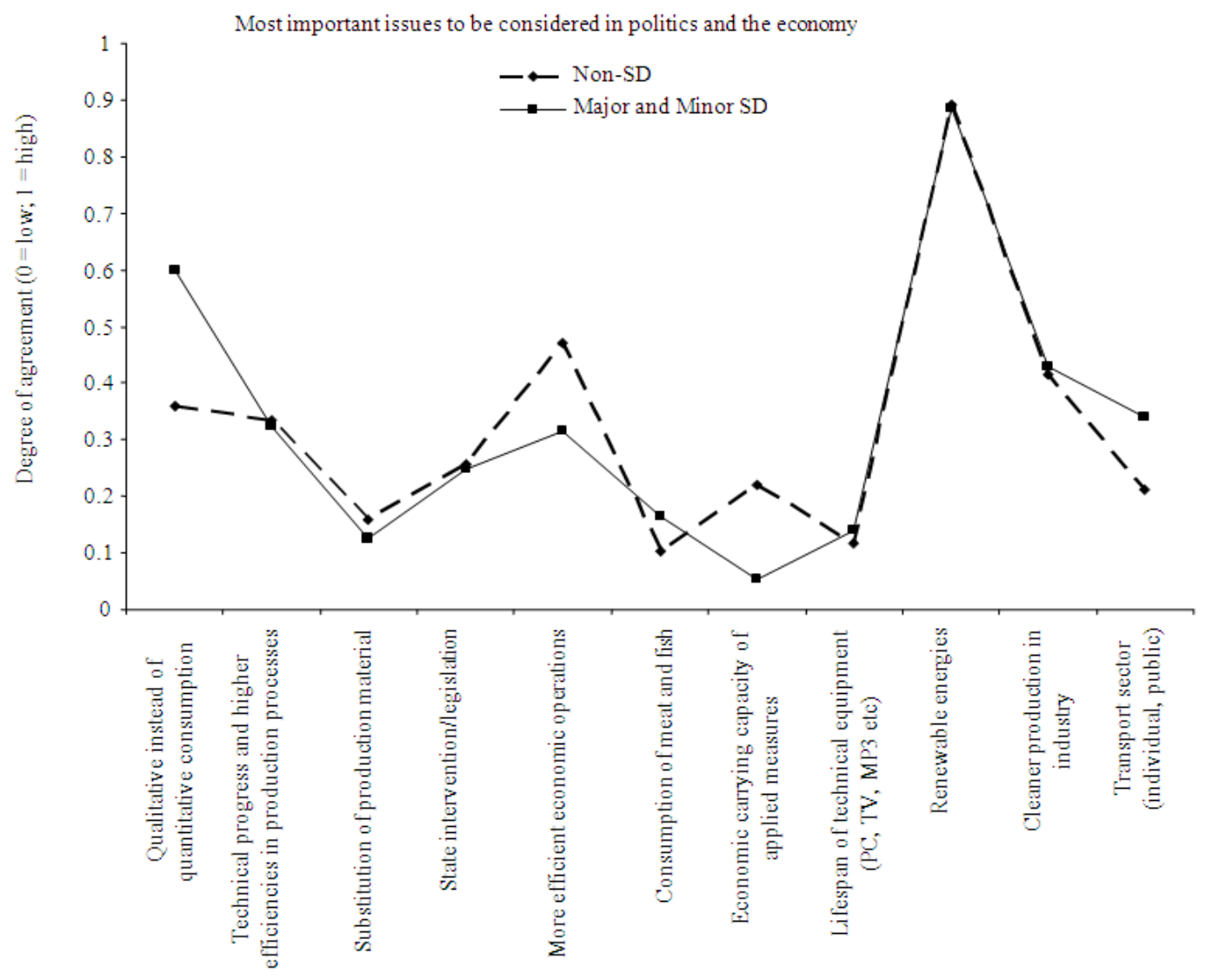

Fig. 5: Differences between (a) SD Non students and (b) SD Major and SD Minor students 
While only $48.2 \%$ of the latter agreed that Leuphana's sustainability teaching would be useful for their professional future, $89.9 \%$ of the SD Minor and 92.6\% of the SD Major students thought so. Interestingly, $49.2 \%$ of the SD Minor and only $35.2 \%$ of the SD Major students checked that it would 'certainly' be useful for them.

Previous vocational education and other work experiences: Significantly more SD Non (36.3\%) and SD Minor students (32.2\%) than SD Major students (14.7\%) indicated that they had finished a vocational training before coming to the university. However, when asked about other experiences before their study start, SD Non students showed the highest rate (33.9\%) of not having acquired any experience apart from vocational training and some measure of work experiences.

About 22.0\% of the SD Major students had done a voluntary social or ecological year, which is a significantly higher share than that of SD Non students (6.4\%). Interestingly, SD Minor students had been abroad (for at least three months) before their study start (46.6\%) compared with the highly significantly lower shares of $15.8 \%$ of the SD Non and $16.5 \%$ of the SD Major students.

\section{DISCUSSION}

Reliability of results: In terms of the reliability of the study results, some limitations have to be noted. First, since both studies were designed as sample studies, rather than pre- and post-test surveys, they only picture the attitudinal perspectives of students after they had taken a course. Not having assessed the level of the students' sustainability knowledge and attitude from the time before they attended university, the study results do not allow drawing conclusions about possible changes in their perceptions, attitudes and behaviors that were due to educational inputs they received.

Second, the second study required voluntary participation from the students. This might have led to a process of higher self-selection of students that were involved in this survey. This holds true particularly for the group of SD Non students as for them a sample survey had been carried out. Again, this might have caused positive self-selection by the students who had already been interested in the field. Hence, in a complete survey for this third student group, even clearer differences between the three student groups might have been observed.
Third, a set of open instead of categorized questions might have revealed students' 'real' knowledge about and attitude towards sustainability, particularly with respect to their understanding of the sustainability concept and their opinion about important political issues that should be considered on the political agenda.

Fourth, not only has Leuphana declared sustainability along with humanism and action orientation as one of the university's key principles, it has also been aiming at implementing sustainable oncampus operations. For the Bachelor study programs not only major and minor studies have been put into practice, but also instruction in sustainability for all first semester students This 'all-round contact' with sustainability might have contributed to a feeling of 'must answer pro sustainability', although students possibly did not have completely positive feelings toward the concept.

General discussion of results: In general, the acceptance of both the Leuphana semester and the module 'Sustainability bears responsibility' is clearly declared among students. Didactical key elements are well regarded with significant differences between the different study courses. Considering both, the relatively high acceptance of the HESD approach described and the agreement of the main aspects of sustainability, the implementation of sustainability in the Leuphana semester may well be rated successful. This clearly supports a whole system change in higher education as discussed in Sterling (2001). The findings are even more noteworthy as the study's target was not only students who were already interested in sustainability anyway and made it an aspect of their choice of study programs, on the contrary, the study reached out as well to those students who chose a different subject and were not planning to work in that area.

It is particularly noticeable that a high majority of all students showed a sophisticated understanding of the concept of sustainability and agreed with the values associated. However, a tendency to an ecological understanding of sustainability can be observed. Comparing the results of the study on environmental awareness in Germany, which was commissioned by the German Federal Environment Ministry and the Federal Environment Agency in 2008, with the present study, Leuphana's Bachelor students between the ages of 18 and 24 showed a higher acceptance of the sustainable development concept than the average student and apprentice of the same age. While an average of $53.8 \%$ of German students stated that "we should not use more resources than can grow again in 
the same time”, $68.9 \%$ of Leuphana's Bachelor students were of the opinion that sustainability means "not using more resources than can grow again in the same time". For $67.1 \%$ of Leuphana's Bachelor students the term 'sustainability' stands for "inter- and intergenerational equal opportunities", whereas $50.8 \%$ of the German students of the same age believe that "there should be justice between generations, we should not despoil the environment at following generation's cost". Interestingly, $86.0 \%$ of Bachelor students at Leuphana indicated that renewable energies are measures to consider in future discussions about sustainable development, whereas only $55.4 \%$ of German students overall said that "society needs to strategically switch to renewables".

In terms of the three student groups, SD Non and SD Major students did not show highly surprising results, whereas students doing sustainability studies in their minor clearly stood out. Even though those students exhibited similar results in terms of sustainability literacy to SD Majors, they put much more emphasis on the social dimension of sustainability than did either of the other two study groups. Moreover, the SD Minors group tended to be more open and positive towards the Leuphana education model than SD Major and SD Non students. These characteristics might partly be explained by their high international experience: With a share of $46.6 \%$, a highly significant greater number of SD Minors had been abroad for at least three months before starting their studies, as compared with the shares of $15.8 \%$ for the SD Non and $16.5 \%$ for the SD Major students. These results suggest that the chosen education model may not only be attractive to inherently sustainability affiliated prospective students but particularly also to open, tolerant and cosmopolitan young people in general. Therefore it might be effective in educating not just 'change agents' within the major study program in sustainability science, but also within minor courses in sustainable development.

\section{CONCLUSION}

In many ways, HESD provides good prospects for an innovative academic education. Whether this will be achieved, is of course a matter of implementation. For a long-term perspective, it seems to be crucial to identify and communicate an added value for students that they can recognize and acknowledge. In doing so, HESD may be seen as a driving force for improvement in teaching and learning.

At Leuphana, the attempt was made to implement a completely new educational model by introducing a 'studium generale' approach for all students in their first semester. With all students working within the module 'science bears responsibility', sustainability plays a major role in that concept. Given the relatively high acceptance rate and the general positive feedback from the two surveys conducted, the implementation process can be considered successful. Students perceive the new study model as a valuable opportunity for both, their personal development and their professional career. The learner-centered approach is connected to students' lifeworld experience, which provides an opportunity to also attract those students that might be less familiar with the sustainability concept.

Furthermore, the chosen approach does not only offer opportunities to make a larger target groups deal with that subject, but may already be recognized as an important aid to decision making for students when deciding on the university they aim to study at. In this way, both the educational model as such and its strong recognition of HESD may function as a branding for the university within the higher education market.

Further research will investigate that aspect in greater detail, examining in a longitudinal study whether there is a long term shift in students' knowledge, norms and beliefs even when they start studying as the model will be more and more settled and well known to those who start their studies with a brand recognition in terms of sustainability. At the same time, through the implementation of a pre-/post assessment, more information will be available about the educational effects of the module on students' learning outcomes.

\section{REFERENCES}

Adomssent, M. and G. Michelsen, 2006. German Academia heading for sustainability? Reflections on policy and practice in teaching, research and institutional innovations. Environ. Educ. Res., 12: 85-99. DOI: $10.1080 / 13504620500527758$

Adomssent, M. and A. Beringer, 2008. Sustainable university research and development: inspecting sustainability in higher education research. Environ. Educ. Res., 14: 607-623. DOI: 10.1080/13504620802464866

Barnett, R., 2004. Learning for an unknown future. Higher Educ. Res. Dev., 23: 247-260. DOI: $10.1080 / 0729436042000235382$

Barth, M. and J. Godemann, 2006. Study Programme Sustainability-a Way to Impart Competencies for Handling Sustainability? In: Higher Education for Sustainability. New Challenges from a Global Perspective, Adomssent, M., J. Godemann, A. Leicht and A. Busch (Eds.). Frankfurt a. M. VAS, ISBN: 978-3-88864-423-8, pp: 198-207. 
Blewitt, J. and C. Cullingford, 2004. The Sustainability Curriculum. The Challenge for Higher Education. 1st Edn., Earthscan, Sterling VA, London, ISBN: 1853839485, pp: 256.

Brand, R. and A. Karvonen, 2006. The ecosystem of expertise: Complementary knowledge for sustainable development. Sustainability: Sci. Practice Policy, 3: 21-31. http://ejournal.nbii.org/archives/vol3iss1/0601004.brand.pdf

Corcoran, P.B., K.E.Walker and A.E.J. Wals, 2004. Case studies, make-your-case studies and case stories: A critique of case study methodology in sustainability in higher education. Environ. Educ. Res., 10 : 7-21. DOI: 10.1080/1350462032000173670

Corcoran, P.B. and A.E.J. Wals, 2004. Higher Education and the Challenge of Sustainability. Problematics, Promise and Practice. 1st Edn., Kluwer Acad. Publ., Dordrecht, ISBN: 1-40202134-8, pp: 355.

Cortese, A.D., 2003. The critical role of higher education in creating a sustainable future. Plann. Higher $\quad$ Educ., $\quad$ 31: 15-22. http://www.aashe.org/documents/resources/pdf/Cor tese_PHE.pdf

Fien, J., 2002. Advancing sustainability in higher education. Issues and opportunities for research. Int. J. Sustain. Higher Educ., 3: 243-253. DOI: 10.1108/14676370210434705

Gough, S. and W. Scott, 2007. Higher Education and Sustainable Development. Paradox and Possibility. 1st Edn., Routledge, London, ISBN: 978-0-41541652-8, pp: 194.

Gruppe, 2004. Memorandum: Hochschule neu denken. Neuorientierung im Horizont der Nachhaltigkeit. Universität Lüneburg Scharnhorststr. http://www.programm-

mgu.ch/de/home/Dienstleistungen/team/holm/Par/0 5/File/memoHochschule.pdf

La Harpe, B. de and I. Thomas, 2009. Curriculum change in universities: Conditions that facilitate education for sustainable development. J. Educ. Sustain. Dev., 3: 75-85. DOI: 10.1177/097340820900300115

Leal, F.W., 2000. Sustainability and University Life. 2nd Edn., Frankfurt am Main, ISBN: 10: 0820448001, pp: 270.
Moore, J., 2005. Barriers and pathways to creating sustainability education programs. Policy, rhetoric and reality. Environ. Educ. Res., 11: 537-555. DOI: 10.1080/13504620500169692

Orr, D., 1994. Earth in Mind: On Education, Environment and the Human. 1st Edn., Island Press, Washington, ISBN: 155963295X, pp: 222.

Scott, W. and S. Gough, 2003. Sustainable Development and Learning. Framing the Issues. 1st Edn., Routledge Falmer, London, ISBN: 0415276489, pp: 192.

Seybold, H. and W. Rieß, 2006. Research in environmental education and Education for sustainable development in Germany: The state of the art. Environ. Educ. Res., 12: 47-63. DOI: 10.1080/13504620500526487

Sterling, S., 2001. Sustainable Education: Re-visioning Learning and Change. 1st Edn., Foxhole, Green Books Ltd, ISBN: 1870098994, pp: 94.

Sterling, S., 2004. Higher Education, Sustainability and the Role of Systemic Learning. In: Higher Education and the Challenge of Sustainability. Problematics, Promise and Practice, Blaze Corcoran, P. and A.E.J. Wals, Arjen (Eds.). Springer Netherlands, Dordrecht, ISBN: 1-40202134-8, pp: 47-70.

Thomas, I., 2004. Sustainability in tertiary curricula: What is stopping it happening? Int. J. Sustain. Higher Educ., 5: 33-47. DOI: 10.1108/14676370410517387

Tilbury, D., 2004. Environmental Education for Sustainability: A Force for Change in Higher Education. In: Higher Education and the Challenge of Sustainability. Problematics, Promise and Practice, Blaze Corcoran, P. and A.E.J. Wals, Arjen (Eds.). Springer Netherlands, Dordrecht, ISBN: 1-4020-2134-8, pp. 97-112.

Wright, T., 2006. The Role of Research in Achieving a Sustainable Future. In: Drivers and Barriers for Implementing Sustainable Development in Higher Education. Paris (Education for Sustainable Development in Action), Holmberg, J. and B.E. Samuelsson (Eds.). Göteborg Workshop, pp: 121-125. http://unesdoc.unesco.org/images/0014/001484/14 8466E.pdf

Wright, T., 2007. Higher education for sustainability. developing a comprehensive research agenda. J. Educ. Sustain. Dev., 1: 101-106. DOI: 10.1177/097340820700100117 